\title{
Profiling Kecepatan Gelombang Geser (Vs) Berdasarkan Pengukuran Mikrotremor Studi Kasus Kecamatan Puger, Jember
}

\author{
Muhammad Reza Shalahuddin Noor, Dwa Desa Warnana, Amien Widodo, dan Arief Alihudien \\ Departemen Teknik Geofisika, Fakultas Teknik Sipil dan Perencanaan, Institut Teknologi Sepuluh \\ Nopember (ITS) \\ e-mail: dwa_desa@geofisika.its.ac.id; ariefalihudien@ymail.com
}

\begin{abstract}
Abstrak-Penelitian ini dilakukan untuk memperkirakan nilai kecepatan gelombang geser (Vs) dan mikrozonasi gempa di kecamatan Puger, Jember. Wilayah kecamatan Puger merupakan daerah yang memiliki dataran alluvial pantai yang luas dan rawan terjadi gempabumi karena terletak pada jalur tektonik. Analisis mikrotremor menggunakan metode HVSR dilakukan di wilayah kecamatan Puger untuk memetakan mikrozonasi gempa di daerah tersebut. Dari pengukuran mikrotremor yang telah dilakukan, didapatkan nilai indeks kerentanan seismik $(\mathrm{Kg})$ berkisar 14.4 - 120 dan estimasi nilai kecepatan gelombang geser pada lapisan sedimen yang didapatkan berkisar 223.07 - $765.71 \mathrm{~m} / \mathrm{s}$.
\end{abstract}

Kata Kunci-Gelombang geser, mikrozonasi, gempabumi, mikrotremor, HVSR, kecamatan Puger.

\section{PENDAHULUAN}

$\mathrm{P}$ ERISTIWA gempa bumi sering kali menimbulkan kerusakan pada bangunan yang terletak jauh dari sumber gempa. Perbedaan tingkat kerusakan pada bangunan mengindikasikan bahwa kondisi lapisan tanah memberikan pengaruh terhadap karakteristik gelombang seismik. Lapisan tanah lunak akan mengamplifikasi frekuensi-frekuensi tertentu dari getaran gempa bumi. Kondisi ini dapat terjadi dengan sangat ekstrem di wilayah yang dilandasi oleh lapisan tanah lunak yang tebal, sehingga terdapat perubahan kekakuan material pada batas antara lapisan batuan dasar dan lapisan sedimen yang dapat menimbulkan amplifikasi [1].

Kabupaten Jember merupakan daerah yang sering terjadi aktivitas seismik yang signifikan dirasakan sejak tahun 1981 hingga 2016. Salah satu peristiwa gempa bumi yang terjadi tahun 2016 (M 6.2) menimbulkan kerusakan ringan hingga berat pada bangunan dan infrastruktur jalan di kota Jember. Hubungan intensitas gempa bumi terhadap kerusakan suatu wilayah dipengaruhi oleh jarak dari sumber gempa, skala gempa, ukuran zona patahan, energi yang dilepaskan batuan, jenis geologi antara sumber dan lokasi setempat serta kondisi geologi lokal [2]. Nilai Vs pada permukaan yang diperoleh dari kurva inversi HVSR yang digunakan untuk klasifikasi tanah berdasarkan kekuatan getaran gempa yang disebabkan efek lokal [3].

Untuk mendapatkan nilai Vs pada lapisan sedimen dalam tanah perlu dilakukan pengambilan data secara konvensional menggunakan borehole. Namun hal tersebut membutuhkan waktu yang cukup lama. Oleh karena itu dilakukan pengukuran mikrotremor yang dapat mengestimasi karakteristik dinamik dari tanah di kecamatan Puger.

\section{METODE}

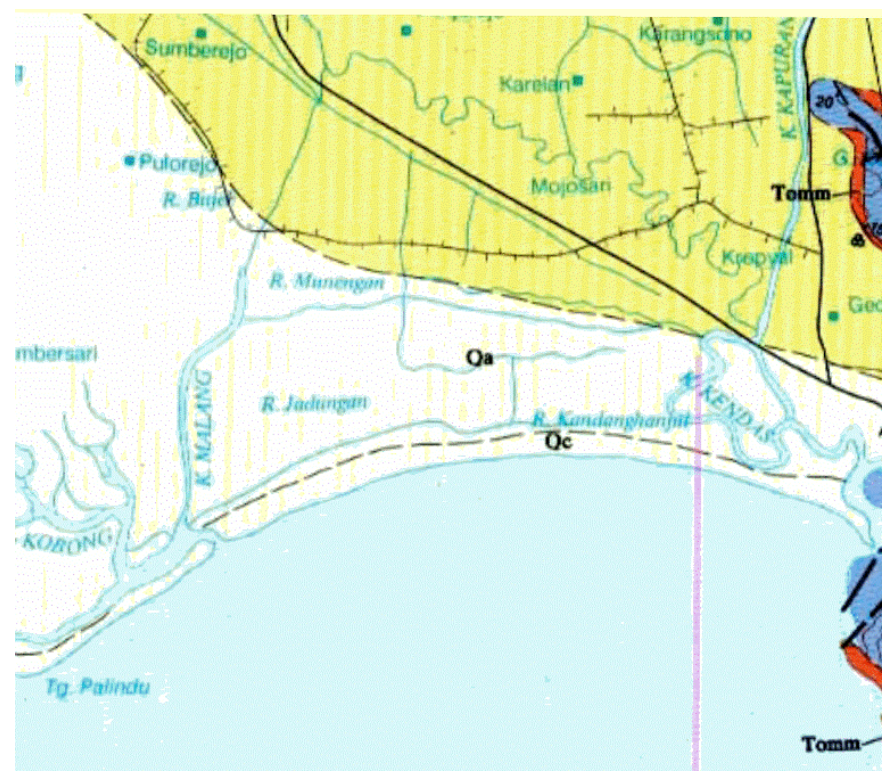

Gambar 1. Peta Geologi Kecamatan Puger (Suwarti dan Suharsono, 1992).

Penelitian ini dilakukan menggunakan seperangkat alat mikrotremor SARA dengan 3 komponen geofon, 2 koponen horizontal (NS dan EW) serta komponen vertikal (Z). Pengukuran dilakukan dengan 30 titik menyebar di kecamatan Puger. Alur penelitian dapat dilihat secara lebih lengkap pada gambar 2. Penelitian diawali dengan mendesain titik akuisisi lapangan sehingga didapatkan informasi mengenai detil lokasi yang terkait dengan akuisisi data mikrotremor. Tahapan selanjutnya adalah akuisisi data mikrotremor yang dilakukan pada desain akuisisi yang telah dibuat sebelumnya.

Data akuisisi yang telah didapatkan kemudian dilakukan pengolahan untuk memperoleh nilai frekuensi natural dan puncak amplitudo. Data akuisisi mikrotremor diolah menggunakan metode HVSR (Horizontal to Vertical Spectrum Ratio) yang kemudian diinversikan untuk mendapatkan nilai 
Vs yang dapat digunakan untuk mengestimasi nilai Vs pada lapisan sedimen di lokasi penelitian.

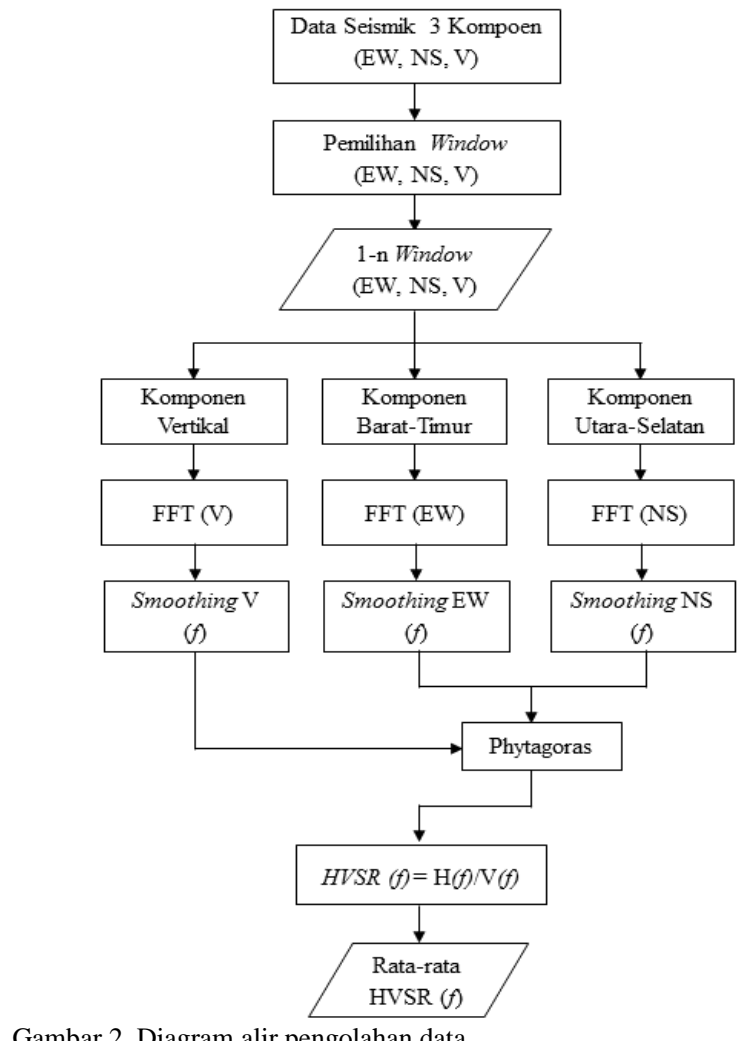

Gambar 2. Diagram alir pengolahan data

\section{A. Mikrotremor Untuk Mikrozonasi Gempabumi}

Metode mikrotremor dapat digunakan dalam penentuan mikrozonasi dari nilai Indeks kerentanan seismik $(\mathrm{Kg})$. Nilai $\mathrm{Kg}$ merupakan suatu parameter yang sangat berhubungan dengan tingkat kerawanan suatu wilayah dari ancaman resiko gempa bumi. Tingkat indeks kerentanan seismik yang tinggi biasanya ditemukan pada daerah dengan frekuensi natural tanah yang rendah. Ini berarti bahwa, pada lapisan sedimen relatif tebal yang menutupi batuan dasar memiliki indeks kerentanan seismik yang tinggi. Pada lapisan sedimen tebal, jika disertai dengan penguatan getaran gelombang seismik (faktor amplifikasi) yang tinggi, maka akan menghasilkan nilai indeks kerentanan tinggi.

Nilai indeks kerentanan seismik diperoleh dengan mengkuadratkan nilai puncak amplitude dari mikrotremor $\left(\mathrm{A}_{\mathrm{o}}\right)$ dibagi dengan nilai frekuensi natural $\left(f_{0}\right)$ [4].

$K g=\frac{\mathrm{Ao}^{2}}{f_{o}}$

\section{B. Pengolahan Data Mikrotremor}

Data yang telah diperoleh kemudian dilakukan pengolahan menggunakan perangkat lunak Geopsy. Selanjutnya dilakukan pemilihan event data gelombang yang stasioner dan dianalisis menggunakan algoritma Fast Fourier Transform (FFT). FFT dihitung pada masing-masing komponen dari sinyal yang dipilih untuk mendapatkan estimasi yang reliabel dari puncak frekuensi HVSR. Kemudian dilakukan proses smoothing dengan koefisien bandwith sebesar 40 sesuai dengan yang diusulkan Konno dan Ohmachi [5]. Data yang sudah difilter kemudian dianalisis menggunakan metode HVSR yang didapat dari perumusan sebagai berikut :

$$
S M=\frac{\sqrt{\left(H S N^{2}+H W E^{2}\right)}}{V S}
$$

Dimana SM adalah spektrum rasio antara komponen horizontal dan vertikal, HSN adalah spektrum mikrotremor komponen horizontal utara-selatan dan HWE adalah spektrum mikrotremor komponen barat-timur. Dari data tersebut kemudian dibuat peta kontur untuk frekuensi natural (fo) dan puncak amplitudo (Ao).

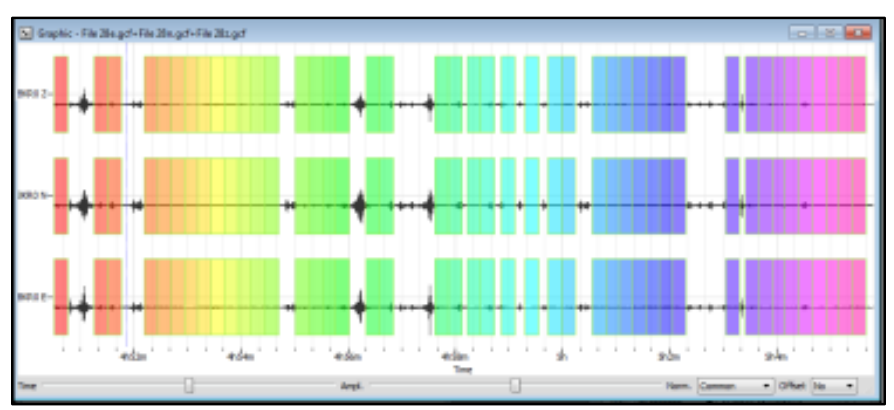

(a)

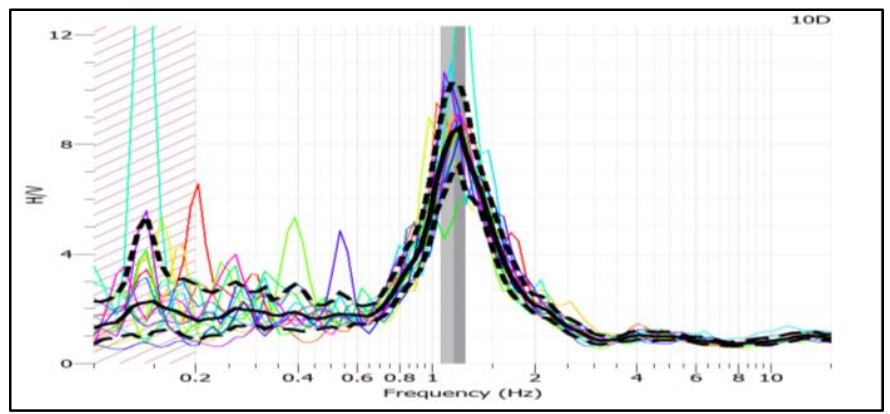

(b)

Gambar 3. (a) Pemilihan window data mikrotremor dengan metode HVSR (b) Kurva HVSR

\section{Pengolahan Inversi Kurva HVSR}

Kurva HVSR kemudian dilakukan proses inversi menggunakan perangkat lunak Open HVSR. Perangkat lunak Open HVSR didasarkan pada metode inversi Monte Carlo. Pada pengembangan perangkat lunak Open HVSR /sebagaimana dipaparkan oleh Herak dalam jurnal Sungkono dan Santosa [6] yang berpendapat bahwa mikrotremor dipengaruhi oleh gelombang badan (body wave) sehingga dipengaruhi oleh 6 parameter yaitu Vs, Vp, Qs, Qp, h dan $\rho$. Oleh karena itu, agar mendapatkan nilai Vs yang akurat diperlukan konstrain pada saat proses inversi kurva HVSR Dalam penelitian ini estimasi nilai Vs dilakukan dengan pendekatan dari data $\mathrm{N}_{\mathrm{SPT}}$ yang diperoleh dari data $\mathrm{CPT}$ (Cone Penetration Test).

\section{HASIL DAN PEMBAHASAN}

Dari analisis kurva HVSR didapatkan nilai frekuensi natural dan puncak amplitudo di kecamatan Puger. Berdasarkan 
analisis dari data yang telah diperoleh, diketahui bahwa daerah pengukuran didominasi oleh frekuensi rendah sampai dengan sedang yang berkisar antara 0,3 - 1,4 Hz. Nilai tersebut ditunjukkan dari persebaran data pengukuran yang terdapat di wilayah kecamatan Puger di dominasi oleh frekuensi natural kecil sehingga dapat diindikasikan bahwa wilayah kecamatan Puger merupakan wilayah dengan kondisi geologi berupa batuan sedimen. Frekuensi natural di wilayah Selatan dan Barat yang merupakan lahan pertanian dan dekat dengan pantai bernilai rendah antara $0.3-0.6 \mathrm{~Hz}$. Sedangkan di wilayah Timur yang merupakan daerah pemukiman dan kantor kecamatan memiliki frekuensi yang sedang antara 0,9 - 1,4 Hz. Daerah yang memiliki nilai frekuensi natural rendah sangat rawan untuk terjadinya multirefleksi gelombang badan atau terjebaknya gelombang pada lapisan sedimen ketika terjadi gempa.

Nilai puncak amplitudo didapatkan berkisar 3 - 9,5. Nilai frekuensi natural dan puncak amplitudo kemudian dilakukan perhitungan sehingga diperoleh nilai indeks kerentanan seismik (Kg) yang berkisar 14,4 - 120. Nilai sebaran puncak amplitudo di daerah Selatan yang dekat dengan daerah pantai memiliki nilai berkisar 5,5 - 7.

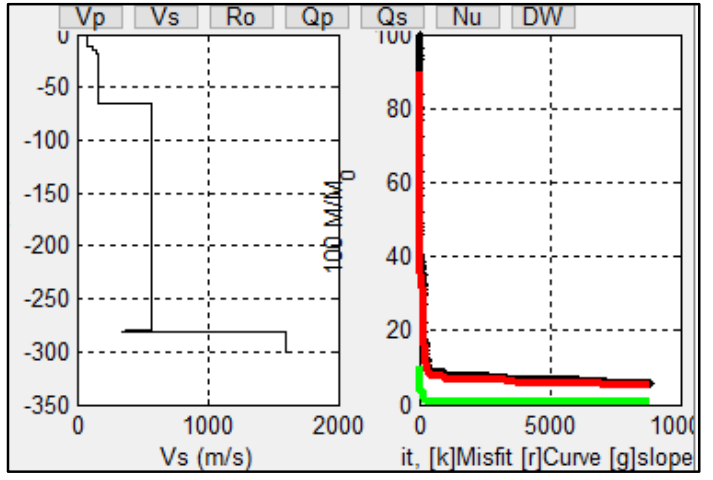

Gambar 4. Grafik sebelah kiri merepresentasikan hubungan Vs dengan kedalaman, sedangkan grafik sebelah kanan menunjukkan hubungan fungsi error dan perubahan bentuk model gelombang.

Berdasarkan peta persebaran nilai Indeks Kerentanan Seismik (gambar 5) dapat diketahui bahwa nilai $\mathrm{Kg}$ di daerah penelitian memiliki nilai yang berkisar antara 14,4 - 120 . Wilayah Selatan pada lokasi penelitian memiliki indeks kerentanan seismik yang tinggi antara $85-120$.

\section{Peta Sebaran Nilai Kerentanan Seismik}

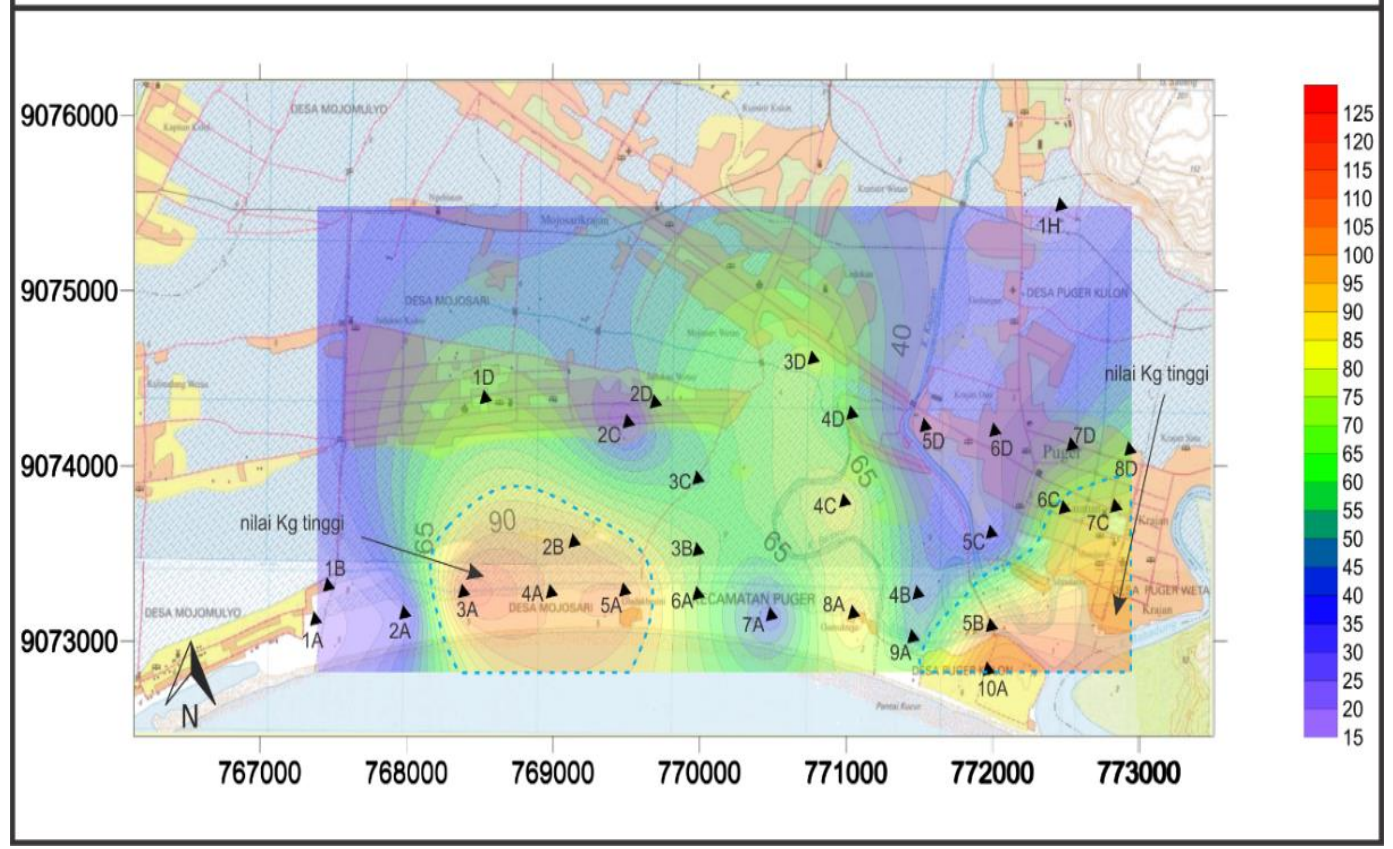

Gambar 5. Persebaran nilai indeks kerentanan seismik 


\section{Peta Sebaran Nilai Vs di Lapisan Sedimen}

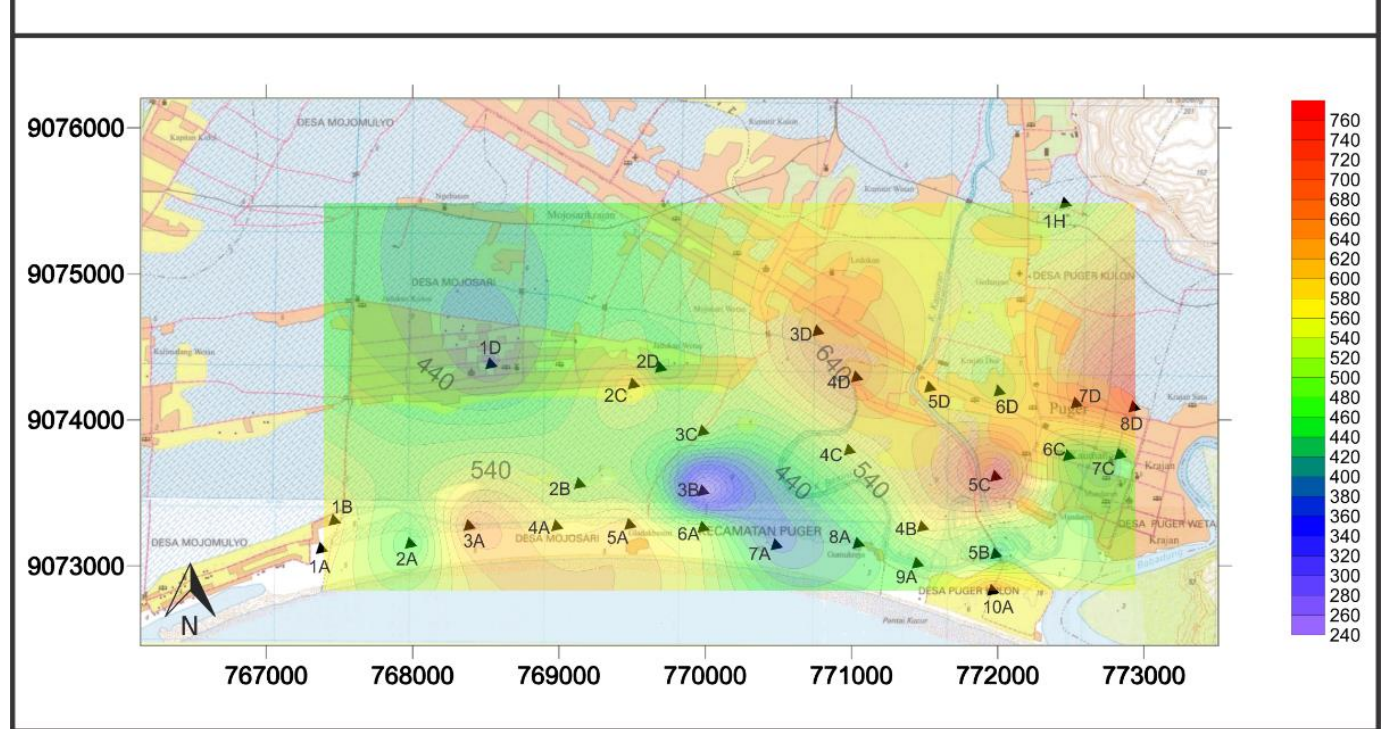

Gambar 6. Persebaran nilai kecepatan gelombang geser (Vs) pada lapisan sedimen

\section{KESIMPULAN}

Hasil analisis pengukuran mikrotremor menggunakan metode HVSR di wilayah kecamatan Puger adalah:

a) Persebaran nilai frekuensi natural (fo) dengan nilai antara $0,3-1,4 \mathrm{~Hz}$ dan nilai puncak amplitudo di kecamatan Puger berkisar 2,6 - 9,1.

b) Nilai indeks kerentanan seismik (Kg) pada wilayah kecamatan Puger berkisar 14,4 - 120. Nilai (Kg) tinggi berada di wilayah Selatan dan Timur kecamatan Puger.

c) Persebaran nilai kecepatan gelombang geser (Vs) di wilayah kecamatan Puger berkisar 223.07 - $765.71 \mathrm{~m} / \mathrm{s}$.

\section{UCAPAN TERIMA KASIH}

Penulis mengucapkan terimakasih kepada Program Penelitian Hibah Pekerti 2017.

\section{DAFTAR PUSTAKA}

Likuifaksi Tanah Pasiran Di Kota Padang Berdasarkan Metode Mikrotremor," 2013.

[2] I. Towhata, Geotechnical Earthquake Engineering. Berlin, Heidelberg: Springer Berlin Heidelberg, 2008.

[3] A. Roser, J., Gosar, "Determination of Vs30 for seismic ground classifications in the Ljubljana area. Slovenia," 2010.

[4] Y. Nakamura, "Clear identification of fundamental idea of Nakamura's technique and its applications," Proc. 12th world Conf. ..., p. Paper no. 2656, 2000.

[5] T. O. Katsuaki Konno, "Ground-motion characteristics Estimated from Spectral Ratios Between Horizontal and Vertical Components of Microtremor," Bull. Seismol. Soc. Am., vol. 88, no. 1, pp. 228$241,1988$.

[6] S. B.J. Santosa, "KARAKTERISASI KURVA HORIZONTAL-TOVERTICAL SPECTRAL RATIO: KAJIAN LITERATUR DAN PERMODELAN,"J. NEUTRINO, Mar. 2012. 